\title{
Antenatal diagnosis of aneurysmal malformation of the vein of Galen
}

\author{
Parth J Darji, ${ }^{1}$ Viplav S Gandhi, ${ }^{2}$ Hiral Banker, ${ }^{2}$ Hemang Chaudhari ${ }^{3}$
}

'Department of Radiology, NHL MMC, Ahmedabad, Gujarat, India

2Department of Radiology, VSGH, Ahmedabad, Gujarat, India

${ }^{3}$ Department of Radiology, SMT SCL Municipal General Hospital and NHL Municipal Medical College, Ahmedabad, Gujarat, India

\section{Correspondence to} Dr Parth J Darji, parthtaylor@gmail.com

Accepted 20 November 2015

\section{SUMMARY}

Vein of Galen malformation (VGAM) results from an aneurysmal aberration with an arteriovenous shunting of blood. Vein of Galen aneurysmal malformations are the most frequent arteriovenous malformations in infants and fetuses. The congenital malformation develops during weeks 6-11 of fetal development. Infants often die from high-output congestive heart failure.

\section{BACKGROUND}

This case is important because vein of Galen malformation (VGAM) is a rare congenital anomaly that often increases in size with advancing age and is associated with hydrocephalus, seizures, intracranial haemorrhage, heart failure and even resultant death. So early diagnosis and treatment is important in order to avoid such consequences.

\section{CASE PRESENTATION}

A 25-year-old woman with an 8-month history of amenorrhoea presented to hospital for routine antenatal check-up and was advised sonography for fetal wellbeing. She was a second gravida with one live child and no known previous congenital malformations.

\section{INVESTIGATIONS}

Ultrasonography examination revealed that fetal maturity was 31 weeks 5 days. All fetal biometric parameters were correlating with the mother's gestational age according to her last menstrual period. We identified a $24 \times 15 \mathrm{~mm}$ solitary, oval cystic lesion in the midline in the cranium extending into the right paramedian region of the posterior fossa.
The lesion appeared to be separate from the occipital horns of the lateral ventricles. Both cerebelli were normal. Ventricles with choroid plexuses were normal. No other abnormalities were found in the cranium. On colour Doppler, the lesion showed characteristic bidirectional blood flow (figure 1).

No other gross congenital anomalies were detected. The fetus was found to have mild cardiomegaly with situs solitus. Sonographic evaluation of the fetal heart did not reveal any other abnormality to justify the cause of the cardiomegaly.

Diagnosis of aneurysmal malformation of vein of Galen was made based on sonographic features and on the mild cardiomegaly.

\section{OUTCOME AND FOLLOW-UP}

The patient was delivered at full term through vaginal route. Physical examination of the baby was unremarkable. The baby was called for post-natal evaluation at the radiology department on the second day. On cranial sonography, a $32 \times 33 \mathrm{~mm}$ cystic lesion was found in the midline and right paramedian region in the posterior fossa showing bidirectional blood flow correlating with antenatal findings (figure 2). No other abnormalities were found in the cranium. Echocardiography showed mild cardiomegaly with otherwise normal morphology, signifying high output as the cause of cardiomegaly.

Antenatal diagnosis of VGAM was confirmed. On discharge from hospital on the fifth postpartum day, we explained the need for CT angiography and other interventions to the relatives of

\section{CSLinked}

http://dx.doi.org/10.1136 bcr-2012-006529

CrossMark

To cite: Darji PJ Gandhi VS, Banker $\mathrm{H}$, et al. BMJ Case Rep Published online: [please include Day Month Year] doi:10.1136/ bcr-2015-213785
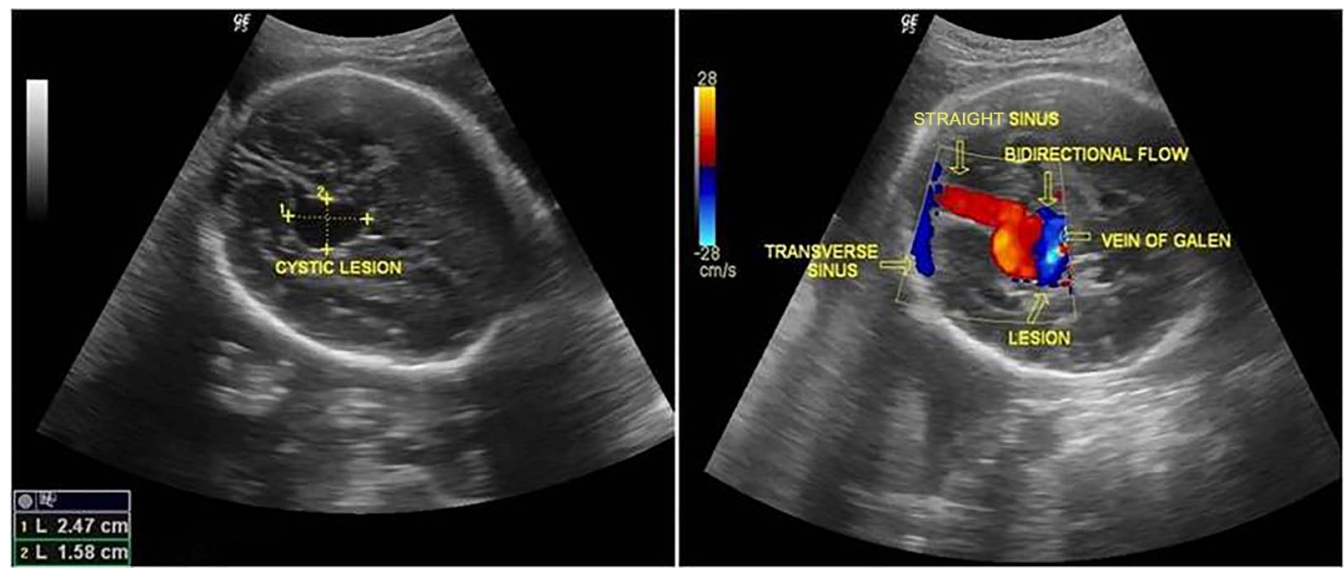

Figure 1 Antenatal ultrasonography image showing cystic lesion in posterior fossa that, on Doppler, showed bidirectional colour flow-vein of Galen malformation. 

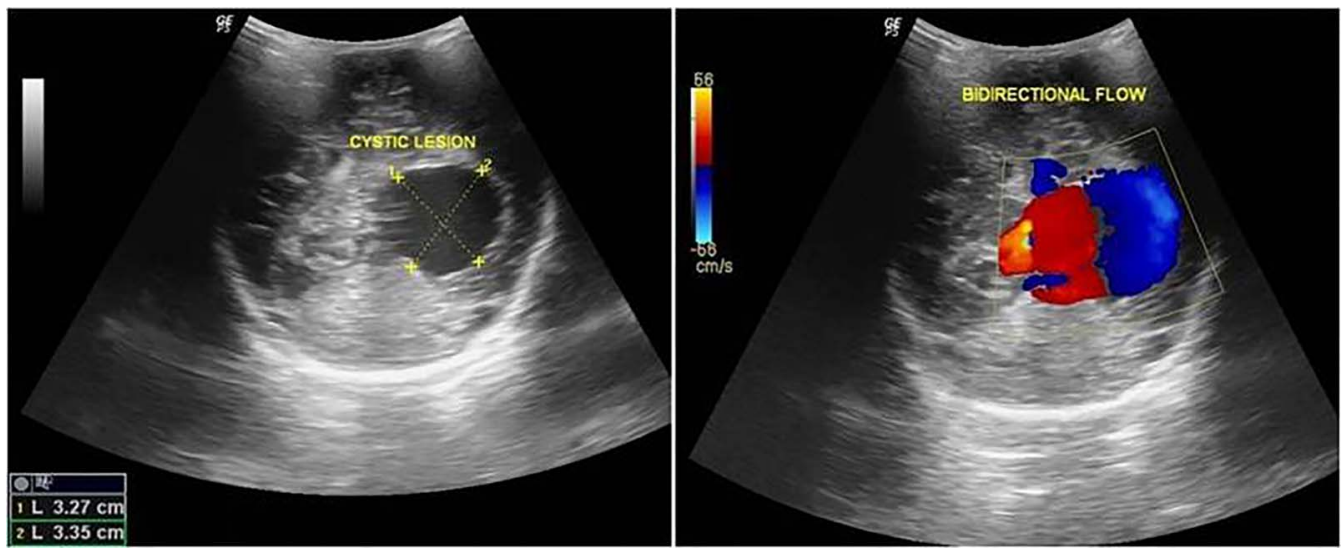

Figure 2 Postnatal sonography image confirming the antenatal findings with aneurysmal dilation of the vein, with bidirectional flow.

the patient. For these, the patient was referred to a specialist centre. Unfortunately, the patient was lost to follow-up.

\section{DISCUSSION}

The vein of Galen is located under the cerebral hemispheres and drains the anterior and central regions of the brain. VGAM results from an aneurysmal aberration with arteriovenous shunting of blood due to either thalamic arteriovenous malformation or a choroidal arteriovenous fistula.

Vein of Galen aneurysmal malformations are the most frequent arteriovenous malformations in infants and fetuses. ${ }^{1}$ The malformation increases greatly in size with age, although the mechanism of the increase is unknown. ${ }^{2}$ The right side cardiac chambers and pulmonary arteries also develop mild to severe dilation. ${ }^{3}$ The congenital malformation develops during weeks 6-11 of fetal development.

Frequency: unknown

Race: VGAM occurs in all races

Sex: Boys and girls are affected equally

Age: VGAM is a congenital malformation; therefore, it may present at birth or in early childhood

It commonly presents in the neonatal period, although it may present in early childhood. Malformations often lead to cardiac failure, cranial bruits and hydrocephaly, and subarachnoid haemorrhage and seizures in neonates. ${ }^{4}$ Heart failure is due to the size of the arteriovenous shunt, which can steal $80 \%$ or more of cardiac output, with large volumes of blood under high pressure returning to the right heart and pulmonary circulation, and sinus venosus atrial septal defects. ${ }^{3}{ }^{4}$ It is also the most common cause of death in such patients. ${ }^{5}$

\section{Imaging studies}

\section{Cranial ultrasound}

- This will help to localise or identify the lesion.

- Doppler studies can help further to understand the haemodynamics of the lesion.

\section{Cranial MRI and/or CT scan}

- These studies will help confirm diagnosis and define the degree of involvement. Imaging studies will also help determine any accompanying hydrocephalus. Cerebral MRI shows large flow void in the central region with enlarged straight sinus and drainage to transverse sinuses.

- MR angiography can help to delineate vascular supply. MRI venogram shows VGAM with draining veins.
Cranial angiography: Cranial angiography is required to define the extent of aneurysmal dilation and details for arterial feeders. Venogram shows draining vasculature for VGAM.

Cardiac ultrasound: This study may be indicated to assess left ventricular function.

\section{Medication summary}

- No specific medical therapy is available

- Seizures usually are managed with antiepileptics. ${ }^{6}$

\section{Patient care}

- Infants who undergo surgical ligation or selective embolisation should be reimaged to assess results of the therapeutic intervention

- Head circumference measurements should be obtained in patients who undergo ventriculoperitoneal shunt to treat hydrocephalus. The patient should be monitored for the development of hydrocephalus.

\section{Complications}

Complications usually associated with VGAMs are usually intracranial haemorrhages. ${ }^{7}$ Over half the patients with VGAM have a malformation that cannot be corrected. Patients frequently die in the neonatal period or in early infancy. Studies have shown that $77 \%$ of untreated cases result in mortality. ${ }^{8}$ Even after surgical treatment, the mortality rate remains as high as $39.4 \% .^{8}$

\section{Learning points}

- Vein of Galen malformation is an uncommon congenital malformation that should be kept in consideration for diagnosis if imaging features are suggestive.

- Vein of Galen malformation may be mistaken for a cystic lesion of the brain if no colour Doppler is performed. Colour Doppler helps to differentiate cystic lesions from vascular aneurysms.

- Vein of Galen malformations are associated with hydrocephalus, seizures, intracranial haemorrhage, heart failure and death. So early diagnosis and treatment is important in order to avoid such consequences.

Competing interests None declared. 
Patient consent Obtained.

Provenance and peer review Not commissioned; externally peer reviewed.

\section{REFERENCES}

1 O'Brien M, Schechter M. Arteriovenous malformations involving the Galenic system. Am J Roentgenol Radium Ther Nucl Med 1970;110:50-5.

2 Takashima S, Becker LE. Neuropathology of cerebral arteriovenous malformations in children. J Neurol Neurosurg Psychiatry 1980;43:380-5.

3 McElhinney DB, Halbach VV, Silverman NH, et al. Congenital cardiac anomalies with vein of Galen malformations in infants. Arch Dis Child 1998;78:548-51.
4 Nicholson AA, Hourihan MD, Hayward C. Arteriovenous malformations involving the vein of Galen. Arch Dis Child 1989;64:1653-5.

5 Johnston IH, Whittle IR, Besser M, et al. Vein of Galen malformation: diagnosis and management. Neurosurgery 1987;20:747-58.

6 Chatterjee S. Antiepileptic drugs. Molecules of the Millenium. Indian J Pharmacol. http://medind.nic.in/ibi/t01/i3/ibit01i3p229.pdf. Retrieved 6 December 2009.

7 Meyers PM, Halbach VV, Phatouros CP, et al. Hemorrhagic complications in vein of Galen malformations. Ann Neurol 2000;47:748-55.

8 Alexander MJ, Spetzler RF. Pediatric neurovascular disease: surgical, endovascular, and medical management. New York: Thieme Medical Publishers, 2005. ISBN: 9781588903686

Copyright 2015 BMJ Publishing Group. All rights reserved. For permission to reuse any of this content visit http://group.bmj.com/group/rights-licensing/permissions.

BMJ Case Report Fellows may re-use this article for personal use and teaching without any further permission.

Become a Fellow of BMJ Case Reports today and you can:

- Submit as many cases as you like

- Enjoy fast sympathetic peer review and rapid publication of accepted articles

- Access all the published articles

- Re-use any of the published material for personal use and teaching without further permission

For information on Institutional Fellowships contact consortiasales@bmjgroup.com

Visit casereports.bmj.com for more articles like this and to become a Fellow 